\title{
CONCEPTUAL ALGORITHMIC INTERFACE OF THE INFORMATIONAL MANAGEMENT PRECEDENT TO HUMAN MATERIAL ACTIVITIES
}

\author{
Tudor LEAHU \\ Free International University of Moldova \\ leahu.ts@mail.ru \\ Sergiu ȘIȘIANU \\ Free International University of Moldova \\ sergeteo7@yahoo.co.uk \\ Alexandr GRECU \\ Free International University of Moldova \\ alexandrgrecu1972@gmail.com
}

\begin{abstract}
There are founded the functional role, determined the place in the unitary information system, emphasized the significant social and professional importance of the mathematical resources, which in economic information processes are realized in different types and groups of algorithms in various categories - textual, graphic, analytical, mathematical, etc. In this paper, are elucidated the groups of algorithms in the form of mathematical formulas, which are solving the rate-setting, settlement and current prevision issues of the human economic activities.According to the content essence of the economic management functions, these algorithms, based on their elaboration and application succession, are systematized and organized in subsystems with the same names as previous nominated groups. The composition and structure of this category of informatics resources, which forms the algorithmic entourage of a domain, are determined.
\end{abstract}

Keywords: conceptual algorithmic entourage, composition, content, informatics issues preceding economic material activities

JEL Classification: M29, O33, O14

DOI: $10.24818 / \mathrm{ie} 2020.05 .06$

\section{Introduction}

Among the contributing components of the economic informatics activities realization the mathematical resources have the decisive functional importance. Although they seem only a formal descriptive interface, essentially, it is obvious that their absence does not practically allow any works initiation and execution. Such significance is explained by the fact that no event or object could be perceived without the initial knowledge of the logic of their organization, structuring, processing and consumption.

That is why the penetration into the essence of any of its activity and resources requires the availability of a certain amount of rules and a succession of their application, which is considered an algorithmization in the informational domain, related to a variety of resources, such as mathematical ones. The involvement of these resources is inevitable, regardless of how the information process is carried out, either manual or automatic. 
It is obvious from mentioned above, that mathematical resources have the primordial value in the informational aspect, conditioned by their initial character in studying and ensuring the functioning of any activity and participant of its realization.

Therefore, the role and importance of these resources exerts decisive influence all over other multiple interfaces, subsequently developed or modified, with the same purpose of the above nominated activities effectuation. All algorithms describing the process of solving a problem or a complex, subsystem and system of problems constitute their algorithmic entourage.

Consistency of adequacy and accuracy of the algorithms of information products values obtaining largely depend on the quality and volume of the material and financial activities results. Authenticity of the algorithms of organization, structuring, processing and use of the information units values depends on the composition and quality of all basic informatics resources, such as informational, programmed, technological and economic.

The extensive and profound influence of the examined interface is motivated by the fact that the composition and structure of other basic informatics resources are determined on its basis [1, 407-408; 2, 85-86; 3, 303].

\section{Content}

\subsection{Conceptual algorithmic entourage of rate-setting and settlement issues of the economic material activities}

According to this concept and starting from the functional meaning of the economic informational products, the following two classes of issues (subsystems) are highlighted:

1) issues of information subsystems previous to the economic material activities;

2) issues of the subsystems following these activities.

Among the issues of subsystems belonging to the first class are considered the rate-setting, settlement and prediction, but among the issues belonging to the second class of subsystems basic are the issues of accounting, statistics and economic analysis.

Depending on the reflective area of the informational products, the rate-setting issues are of a primary (algorithms (1)-(3)) and generalized (algorithms (7)-(8)) nature. First ones are solved by multiple measurements of the natural economic resources (materials and time) consumption dimensions with their subsequent evaluation in cost units returning to a constructive or technological unit and their totalization (summation, generalization) $[1,407 ; 3,303-304 ; 5,228$ $-232 ; 6,338-343 ; 7,109$ - 117].

In this case the value of the primary consumption norm is calculated according to the conceptual algorithms:

For a technological $(1 t)$ or constructive $(1 c)$ primary unit $i$ in value expression:

$$
N_{i v a l}^{1 t(c)}=n_{1 i}^{1 t(c) v a l}+n_{2 i}^{1 t(c) v a l}+\ldots+n_{j i}^{1 t(c) v a l}
$$

where: $N_{\text {ival }}^{1 t}$ - primary norm (in value expression) of the consumption of all resources produced during the effectuation (achieving, fabrication) of a technological (constructive) constitutive unit (e.g. technological operation, part); $n_{j i}^{1 t(c) v a l}$ - primary norm (in value expression) of each consumption resource $j$ for realization(fabrication) of a technological (constructive) unit $i ; i=\overleftarrow{1, r}$ - composition of technological (constructive) units; $j=\overline{1, q}$ consumed resources composition.

This algorithm could be also presented as follows:

$$
N_{i v a l}^{1 t(c)}=\sum_{j=1}^{q} n_{j i}^{1 t(c) v a l} .
$$

As noted above, obtaining the $n_{j i}^{1 t(c) v a l}$ values by the natural expression took place by multiple measurements with the most optimal determination, and in cost units - by multiplying the natural dimension of this norm to the unit resources cost norm: 


$$
n_{j i}^{1 t(c) v a l}=n_{j i}^{1 t(c) n a t} \times P(T)_{j}^{1}
$$

where: $P(T)_{j}^{1}$ - estimation norm in cost units ( $P$ - price, $T$-tariff) of a natural resource unit $j$.

Calculation of the generalizing norms dimensions by the natural expression took place based on the systematization of each consumed resource primary norms values of within the constituent (included, initial) technological units in a superior constructive unit of the same category:

$$
N_{k j n a t}^{1 t(c)}=\sum_{i=1}^{r} n_{j i}^{1 t(c) n a t}
$$

where: $k=\overline{1, l}$ - composition of the constitutive technological (constructive) units.

The same norms dimensions in the value expression and related to all consumed resources are determined based on algorithm (3), only instead of $n_{j i}^{1 t(c) n a t}$ it is operated $N_{k j}^{1 t(c) n a t}$ :

$$
N_{j k v a l}^{1 t(c)}=\sum_{i=1}^{r} \sum_{j=1}^{q} N_{j i}^{1 t(c) n a t} \times P(T)_{j}^{1} .
$$

In addition to the rate-setting issues of consumed resources[1, 408; 3, 304-305; 4, 106-113; 5, $232-240 ; 6,343-347 ; 7,103-109]$, in the composition of information rate-setting and settlement subsystem of economic material activities (R.S.S.E.M.A) are also included the issues of constructive rate-setting (settlement) (algorithm(6)).Their essence is reduced to determining the applicability (normed number) of the lower construction units in a superior assembly unit, obtained on the next assembly stage $n+1$. Next assembly stage $(n+1)$ is taken into account, initial starting with the first one, and then - with the previous $(n)$ stage, the assembly units applicability is known.

To find out this applicability at the next stage $(n+1)$ or final (finite product and activity), is sufficiently to multiply the applicability of the inferior constructive units (from the initial or previous stage) to the applicability of the next assembly stage constructive units, which includes the units at stage $n$, in turn, and the constitutive unit being included in the next assembly stage.

Then the general algorithm of such calculations is as follows:

$$
A_{n+1}^{q 1 m}=A_{n}^{q 1 t} \times A_{n+1}^{t 1 m},
$$

where: $A_{n+1}^{q 1 m}$ - applicability (normed number) of the lower constructive unit $q$ at the assembly stage $n+1$ in a higher constructive unit $m$, included in the next assembly unit stage $(n+2) ; A_{n}^{q 1 t}$ constructive unit $q$ applicability in the initial assembly unit stage $n$ in a constructive unit from the next assembly stage $n+1 ; A_{n+1}^{t 1 m}$ - applicability of the constructive unit on assembly stage $n+1$ in a constructive unit $m$ from the next assembly stage $(n+2)[1,408-409 ; 4,114-123]$.

Observing the settlement issues (algorithms ((7)-(8)), their solving in daily economic reality ends with the elaboration of certain documentation of an administrative, constructive and technological content, according them are organized (regulated) the material activities. That's why those problems algorithms are textual, very concrete and based on pure real objects and works. For given reasons they are the most variable by content and composition, thereby not allowing easily and fully their generalization (standardization). Algorithms of determining the time limit, realization and respecting level of the settlement tasks, initially given to the executors could be subjected to this procedure:

$$
\begin{gathered}
\pm \Delta T=\left(T_{s-} T_{f}\right), \\
\text { or } \Delta V=\left(V_{p l-} V_{r}\right) \times 100 ;
\end{gathered}
$$

where: $T_{s}$ is the set term for task realization, and $T_{f}$ the de facto term; $V_{p l}$-planned works volume, and $V_{r}$-real executed volume. 


\subsection{Conceptual algorithmic entourage of the issues of current economic material activities prediction}

\subsubsection{General formulas of the optimizing economic resources algorithms}

According to the content and pursued goals, two varieties of current prediction are highlighted: optimization and linear. The issues of optimization are unique, among those of economic analysis, as they are formalized by the economic-mathematical modelling. Their resolving requires the preliminary elaboration of two groups of algorithms:

A. Algorithms of extreme values determination of the planned fabrication volume optimizing criteria[1, 409-410; 3, 306; 5, 240 - 243; 6, 347 - 349, 7, 153 -156]:

1) criteria algorithm of maximizing the obtained benefit dimension as a result of finite products commercialization (accomplished activities) $\left(F_{1}\right)$ :

$$
F_{1}=\sum_{i=1}^{n}\left(C_{i}^{1}-S_{i}^{1}\right) \times X_{i} \rightarrow \max ;
$$

where: $i=\overline{1, n}$ - composition (number) of the finite products names (accomplished activities) according to the fabrication plan; $C_{i}^{1}$-commercialization price of a finite products unit(accomplished activities) $i ; S_{i}^{1}$ - the price cost (sum of incurred expenses) of a finite products unit (accomplished activities) $i$; $X_{i}$-fabrication volume plan (units number) of each finite product or realization of each activity $i$;

2)criteria algorithm of maximizing the finite products volume fabrication (carried out activities) expressed by the commercialization price $\left(F_{2}\right)$ :

$$
F_{2}=\sum_{i=1}^{n} C_{i}^{1} \times X_{i} \rightarrow \max ;
$$

3) criteria algorithm of minimizing the finite products volume fabrication (carried out activities) expressed in cost prices $\left(F_{3}\right)$ :

$$
F_{3}=\sum_{i=1}^{n} S_{i}^{1} \times X_{i} \rightarrow . \min ;
$$

B. Restrictions algorithms [1, 410; 3, 307-308; 5, 243 - 245; 6, $353-355 ; 7,156$ - 157 ]:

1) restriction algorithm of the planned fabrication volume finite products (accomplished activities) is expressed in natural units:

$$
r_{i} \leq X_{i} \leq R_{i} ; i=\overline{1, n}
$$

where: $r_{i}$ - minimum volume(number) planned of the finite products fabrication (carried out activities) of each name $i ; R_{i}$ - maximum planned volume (number) of fabrication (carried out activities) of each name $i$;

2) restriction algorithm of the operating time fund dimensions of deficient tool:

$$
\sum_{i=1}^{n} t_{j}^{1 i} \times X_{i} \leq A_{j} ; j=\overline{1, m} \text {; }
$$

where: $j=\overline{1, m}$ - composition (number) of the deficient (advanced) tools names involved according to the fabrication plan in each finite product fabrication (activity accomplished) $i$; $A_{j}$ - planned (possible) annual time fund of deficient tool operation, belonging to technological group $j ; t_{j}^{1 i}$ - labourworkmanship time (hours) of finite products unit processing (carried out activity) $i$ with support of deficient tool $j$.

3 )restriction algorithm of the deficient material resources fund dimensions necessary for the fabrication task achievement:

$$
\sum_{i=1}^{n} m_{k}^{1 i} \times X_{i} \leq M_{k}, \mathrm{k}=\overline{1, l}
$$

where: $k=\overline{1, l}$ - composition (number) of the deficient materials names necessary for each finite product fabrication (activity effectuation) $i ; m_{k}^{1 i}$ - consumption norm of deficient material $k$ for the finite product unit fabrication (for carrying out the activity) $i$; $M_{k}$ - fund dimension (volume, number of units) of deficient materials of each $k$-name for the fabrication planned year.

4) restriction algorithm of the remuneration fund dimensions (basic salaries and bonuses), necessary for the fabrication plan fulfilment: 
www.conferenceie.ase.ro

$$
\sum_{i=1}^{n}\left(Z^{1 i}+P^{1 i}\right) \times X_{i} \leq U_{z p}
$$

where: $Z^{1 i}$ - basic normed salary sum paid for the finite product unit fabrication (activity) $i$; $P^{1 i}$ - normed bonuses sum for overachievement the finite product unit fabrication plan (activity) $i ; U_{s p}$ the planning fund for all production fabrication.

5) restriction algorithm of working hours (normed hours - $T$ ) dimensions of the finite product unit fabrication plan (for carrying out the activities):

$$
\sum_{i=1}^{n} \sigma^{1 i} \times X_{i} \leq T
$$

where: $\sigma^{1 i}$ - normed working hours (hours number) total dimension required for the planned finite product unit fabrication (for one unit activities effectuation) $i$ :

Within the issues belonging to the elucidated category, the primordial functional value also have those of optimization of the tools and technologies operation. They are resolved together with the fabrication plan optimization and formally are reduced to determination and algorithmization of the criteria and restrictions.

\subsubsection{General formulas of the current economic linear prediction algorithms}

Only after determining the indicators values of the optimal fabrication plan $X_{i}$ (algorithms ((9) - (16)) the linear prediction activities could start (algorithms ((17)-(22)) [1, 410-411; 3, 313$323 ; 4,108-109 ; 5,246-254 ; 6,356-360 ; 7,158-168]$. First problem of this planning is the evaluation of the optimal fabrication plan indicators $\left(V_{i}\right)$ in cost units:

$$
V_{i}=X_{i} \times P_{s(c)}^{1 i}
$$

where: $P_{S(c)}^{1 i}$ - the price ( $s$-stable; $c$ - commercialization) of a finite product unit (activity) $i$.

Next, based on solving possibility logics, we present the following types of issues:

1) Estimation of the finite products fabrication plan (of carried out works) by each groups necessary tools arrangement at the prediction period start. First we determine the required number of tools to carry out the optimal fabrication task of each group:

$$
n_{d}^{p l}=\frac{T_{d}^{p l}-F_{d}^{p l}}{r_{d}^{1}}
$$

where: $n_{d}^{p l}$ - tools planned number of each technological group $d$, necessary for optimal fabrication plan fulfilment; $T_{d}^{p l}$ - tool working hours volume of the technological group $d$, which the economic unit will have within the predicted term; $F_{d}^{p l}$ - the work timevolume for the sameterm of fabrication plan; $r_{d}^{1}$ - dimension of the annual time fund planned forthetool unit operation belonging to each technological group $d$.

Next we obtain the determination degree of the optimal fabrication plan with deficient tools $\left( \pm \Delta n_{d}\right)$ :

$$
\pm \Delta n_{d}=n_{d}^{p l}-n_{d}^{f a c}
$$

where: $n_{d}^{f a c}$ - de facto tools number of each group $d$ at the prediction period beginning.

2) The needs volume of other resources for basic fabrication plan realization is determined according to the following generalizing algorithm:

$$
R_{q}=\left(\sum_{i=1}^{n} X_{i} \times N_{q}^{1 i}\right)-S_{q}
$$

where: $R_{q}$-needs volume in the $q$ resource for the nominated plan task realization; $N_{q}^{1 i}$ - the norm of resource $q$ consumption of the finite product unit (activity) $i$; $S_{q}$ - resource $q$ balance volume at the planning deadline.

3) Based on various resources needs volume, the sum of the financial resources necessary for their procurement $(C)$ are determined:

$$
C=\sum_{q=1}^{h}=R_{q} \times P_{q}^{1}\left(T_{q}^{1}\right)
$$


where: $q=\overline{1, h}$ - composition (number) of resources names; $P_{q}^{1}\left(T_{q}^{1}\right)$ - price (tariff) of a resources unit $q$; $R q$ - volume, in the natural expression of each resource.

4) Knowing the total commercialization amount (income) ( $V$ ), it is possible to determine the planned benefit dimension $(B)$ for the prescribed period:

$$
B=V-C \text {. }
$$

\section{Conclusions}

1. Any economic management system should initiate its activity by obtaining informational rate-setting, settlement and prediction products;

2. Algorithms of rate-setting and settlement issues, have simple construction, are resolved for a technological or constructive unit, have a primary and generalizing nature and are predominantly obtained by informational results of natural expression;

3. Mathematical resources of the predictive subsystems problems (prognostic, current, operative) have specificity for each planning category;

4. Algorithms of economic-mathematical methods of the information products prognostic could be generalized only with regard to dimensions needs determination in certain resources, which are formally identical to calculating algorithms of the same resources in the current prediction;

5. Algorithms of current optimization and linear prediction are highlighted by content and aims;

6. Algorithms are formalized based on economic-mathematical modelling;

7. For algorithms of these problems it is characteristic to have one or more criteria, their values are optimized by maximizing (minimizing) under conditions of certain restrictions respect;

8. Algorithms of current optimization prediction contribute to solving multivariate issues, and linear ones - to direct calculation solving issues.

\section{References}

[1] T.Ș. Leahu. "Componența conceptuală și esența funcțională a anturajului algoritmic al subsistemelor informaționale economice precedente activităților materiale umane", Proceedings of $34^{\text {th }}$ Annual Congress of the American Romanian Academy of Arts and Sciences (ARA). Development-Connections. "Carol I" National Defence University, Bucharest, Romania, May 18-23 2010. Presses Internationales POLITECHNIQUE. Montréal, Québec, pp.407- 412, 2010.

[2] T. Leahu. "Despre componența anturajului algoritmic al problemelor informaționale economice", Conferința corpului didactico-științific "Bilanțul activității științifice a USM pe anii 1998-1999”, Universitatea de Stat din Moldova. 27 septembrie - 02 octombrie 2000. Rezumatele comunicărilor. Științe fizico-matematice. Chișinău,C.E.al USM, pp. 85-86, 2000.

[3] T. Leahu. "Specificul anturajului algoritmic al problemelor informaţionale economice", Ecuaţii Integrale şi Modelarea Problemelor Aplicative (EIMPA-2005), CZU 330.46, Chişinău, vol. II, pp. 303-314, 2006.

[4] T. Leahu, L. Hâncu. Bazele sistemelor informatice economice. Chișinău, CEP USM, pp. $106-132,2005$.

[5] Y.F. Telnov. Information systems and technologies. Moscow, Unity, pp. 228 - 254, 2012.

[6] G.A. Titorenco. Information systems and managerial technologies. Moscow, Unity, pp. $338-360,2012$

[7] N.G. Tverdohleb. Organization of machine processing of economic information. Kiev, Viscea Scola, pp.103 - 117, 1979. 